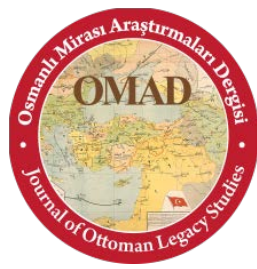

Osmanlı Mirası Araștırmaları Dergisi (OMAD), Cilt 4, Sayı 9, Temmuz 2017, ss. 1-5.

Journal of Ottoman Legacy Studies (JOLS), Volume 4, Issue 9, July 2017, pp. 1-5.

ISSN 2148-5704

DOI Number: 10.17822/omad.2017.61

Geliş Tarihi/Received: 15.08.2016 Kabul Tarihi/Accepted: 22.11.2016

\title{
AZERBAYCAN YERGİ EDEBIYYATINDA BİR ZİRVE: MİRZA ALEKPER SABİR
}

\section{A Peak in Azerbaijan Satire: Mirza Alakbar Sabir}

\section{Kübra KULIYEVA*}

Özet: Edebî bir tür olarak yergi, gülmenin veya eğlenmenin ötesinde, eleştirmenin ve toplumdaki sorunlara, haksızlığa, adaletsizliğe, taassuba karşı durmanın bir aracı olmuştur. Bu bakımdan toplumda sorunların var olması eleştiriyi ve yergiyi doğurur. Yerginin amacı da insanların dikkatini bu sorunlara çekmek olduğu kadar aynı zamanda bu sorunları düzeltmeye çalışmaktır. Azerbaycan edebiyatında yerginin tarihi çok eskilere dayanmakla birlikte hem halk edebiyatında hem de klasik edebiyatta birçok yergi örneği bulmak mümkündür. Bu gelenek yakın geçmişimizde de bulunmaktadır. Bu örneklerin en önde geleni Mirza Alekper Sabir'in şiirleridir. Sabir Azerbaycan yergi edebiyatında eski anlayışı yaratıcılıkla geliştirerek yeni bir dönemin başlangıcı olmuştur. Şiirlerinde topluma ayna tutan şair toplumda gördüğü bütün haksızlık, adaletsizlik, yanlış ve kötülükleri eleştirmiş hatta alaya almış ve bu yolla dikkati çekerek, bahsettiği sorun ve yolsuzlukların düzeltilmesi gerektiğini dile getirmiştir. Yaşadığı dönemde hak ettiği değeri göremeyen şair edebî kuvvetinin de farkında olduğu için tarzından vazgeçmemiş ve edebiyatın zirvesinde olacağını bilerek eser vermeye devam etmiştir.

\section{Anahtar Kelimeler: Mirza Alekper Sabir, Yergi, Azerbaycan Edebiyat1}

Abstract: As a genre of literature, satire has been used as a means for criticism as well as standing up against social problems, inequity, injustice, and bigotry besides being a source of laughter and entertainment. In this respect, social problems often lead to criticism and satire. The aim of satire is to draw attention of society to these problems as well as to eliminate such problems. Whereas the history of satire goes back to earlier periods of Azerbaijan literature, many examples of satire can be found in both folk literature and classical literature. This tradition was also found in the recent past. The most prominent examples of satire are the lyric poems by Mirza Alakbar Sabir. By revolutionizing the early comprehension in Azerbaijan satire with creativity, Sabir had introduced a new era. With his poems as a mirror to reflect the society, the poet criticized and even ridiculed all forms of inequity, injustice, wrongdoing, and perversity that he observed in the society. As a result, he drew attention to such issues and expressed that these problems and abuses had to be eliminated. Although the poet did not receive much appreciation during his life, he persisted on his satirical style as he was well aware of his literary strength, and therefore he continued to create literary works as he knew his works would be at the peak of satire one day.

Key Words: Mirza Alakbar Sabir, Satire, Azerbaijan Literature

\section{Giriş}

Yergi, edebiyatta gülüşün keskin biçimidir. Bu gülüş anlamsız, basit bir gülüş değil, bazen ciddi, uyarıcı bazen de öfkeli, mahvedici bir gülüştür. Yergi hakkında Rus eleştirmen V. G. Belinski şöyle yazar: "Yergide şairin konuya bakış açısı duygularından yüksektir. Burada şair konuyu kendi ruh süzgecinden geçirerek ele alır; genel anlamda burada didaktizme yer yoktur."1

\footnotetext{
* (Doç. Dr.), Azerbaycan Devlet Ekonomi Üniversitesi, Bakü/Azerbaycan, e-mail: qkubra@mail.ru, ORCID: orcid.org/0000-0002-5328-4890

${ }^{1}$ Vissarion Grigoryeviç Belinski, Sobrannıye Soçineniye v Tryox Tomax, C. II, OGIZ, GIXL, M., Moskova 1948, s. 79.
} 
Bilindiği gibi, yergi toplum içindeki sosyal adaletsizlikten doğar. Eğer toplumda adalet yoksa, özgürlük, bağımsızlık gibi düşünceler saldırılara maruz kalıyorsa, insan hakları çiğneniyorsa burada yergi doğar. Yerginin amacı insanları düşündürerek toplumdaki olumsuzluklara dikkat çekmektir. İnsanı var olduğu yerde haksızlıkların, adaletsizliklerin, yolsuzlukların olması kaçınılmaz ve doğaldır, çünkü insan iyi olduğu kadar, her türlü fenalığı yapmaya da eğilimlidir.

Yergide sadece siyaset adamları ve bürokrasi değil, alt tabakalar da eleştiri konusu olabilir. Çünkü toplum içindeki olumsuzluklar o toplumu oluşturan insanların yaptıklarından doğar ve her şeyden önce bunu görmezden gelenlerin bu yolla eleştirilmesi gerekir. Bu yüzden yerginin toplum içinde her zaman yeri olduğu söylenebilir.

Azerbaycan edebiyatında yergi bir edebî cereyan olarak sözlü ve klasik edebiyattan doğmuştur. ${ }^{2}$ Hafif alay veya kinayeli gülüşlere sözlü edebiyatın zengin hazinesindeki mâni, koşma, halk tiyatrosu gibi türlerde rastladığımız gibi, klasik yazılı edebiyatta da tesadüf etmekteyiz. Sözgelimi Fuzuli’nin "Şikâyetname"si XVI. yüzyıl yergisine güzel örnek olabilir. Onun "Selam verdim, rüşvet değildir diye almadılar" sözü döneminde de bugün de meşhurdur. Kuşkusuz, toplum değişmedikçe her zaman güncel olarak kalacaktır.

Azerbaycan şiirinde yergi XVIII. yüzyılın başında ortaya çıkmaya başlamıştır. Baba Bey Şakir, Kasım Bey Zakir ve Seyyit Azim Şirvani ile gelişmeye başlayan yergi, XX. yüzyılın başlarında Mirza Alekper Sabir'in șiiriyle doruk noktasına ulaşmıștır. ${ }^{3}$ O zamana kadar edebiyatımızda yergi bir cereyan olarak henüz biçimlenmemişti, sadece tek tek kişileri eleştiren hicivler yazılmaktaydı ki, buna da yalnız yerginin çekirdeği denebilir.

Yerginin her zaman güncel ve gündemde olmasının başlıca nedeni bütün dönemlerde halkı ileriye değil, geriye götüren bir kısım devlet ve din adamlarının, hurafeye kanan cahil insanların, fakirleri ezen zenginlerin, bilime karşı olan insanların var olmasıdır. XIX. yüzyılda G. Zakir'in, S. A. Şirvani'nin tenkit hedefi döneminin azgın, insanları cehalete sürükleyen bir kısım din adamları, rüşvet verilerek ele geçirilen hâkimler, yüksek mevki sahipleri olmasına rağmen, bugün aynı olayları yaşadığımız halde eleştirilmemesi şaşılacak bir noktadır.

\section{Azerbaycan Yergisinde Sabir}

Hicvetmek için her zaman bir sebep vardır fakat bunun için ortamın olması şarttır. M. A. Sabir'i topluma tanıtan "Molla (Hoca) Nasreddin" dergisi oldu.

Millat neca tarac olur olsun, nə işim var?!

Düşmənlara möhtac olur olsun, na ișim var?!

Qoy man tox olum, özgalar ila nadi karim,

Dünyavü-cahan ac olur, olsun, nə işim var! (s. 5.)

Sabir'in bu şiiri günümüzde de herkesin ezberindedir. Şiirin uzun yıllar daha hafizalarda yaşayacağına eminiz. Çünkü "millet nece tarac olur olsun, ne işim var?!" diyen gamsız ve önemsemez mevki sahipleri her zaman mevcuttur. Burada dikkat çeken bir özellik de şiirin bir ata sözü gibi her dönem için güncelliğini koruyabilmesidir ki, bu da M. A. Sabir'in yaratıcı gücünün bir kanıtıdır.

Sabir'in yaratıcılı̆̆ 1 Azerbaycan şiirinin yeni bir döneminin başlangıcıdır, diyebiliriz. Hatta edebiyat tarihinde yergi şairi olarak bilinen Sabir edebiyatta devrimci yergi gibi yeni bir okulun kurucusudur. ${ }^{4}$ Çünkü Sabir hayat gerçeklerini her yönüyle, olduğu şekilde ifade etmeye çalışıyordu. Sabir, yaratıcılığıyla hayatı ayna gibi yansıtıyordu. Gördüğü fenalıkları, toplumun

\footnotetext{
${ }^{2}$ Alhan Bayramoğlu, "Mirze Alekper Sabir”, Azerbaycan Jurnal, Nu. 1, Bakü 2008, s. 152.

${ }^{3}$ Yadulla Ağazade, Azerbaycan Edebiyatında Satirik Poeziyanın Teşekkülü ve İnkişafi, Bakü 2013, s. 10; İrade Nabiyeva, "Sabir Hakkında Düşüncelerim", Tehsil Problemleri Jurnal, 1 Eylül 2016, s. 32.

${ }^{4}$ Adile Qocayeva, "Büyük Satirik Kasım Bey Zakir ve Onun Maarifçilik Faaliyeti”, Azerbaycan Jurnalı, 4 Ağustos 2009, s. 5.
} 
gelişimini engelleyen yetersizlikleri, kusurları sadece betimlemekle yetinmiyor, bir vatandaş olarak bunların yok edilmesine, kaldırılmasına da çaba gösteriyordu. Sabir halkın anlayabileceği çok basit, anlaşılır bir dille toplumun en zor problemlerini estetik betimleme araçları kullanarak anlatmayı başarıyordu. $\mathrm{O}$, şiir dilini konuşma dili gibi kullandığından fikrini daha kolaylıkla ve zorluk çekmeden okuma yazması olmayan kitleye bile ulaştırabiliyordu.

Sabir'in gülüşü bazan o kadar güçlü ve keskindir ki, istihza seviyesine yükselir. "Fehle" ("İşçi") şiirinde insan yerine konulmayan sıradan işçilerin durumunu yergi diliyle halka ulaştıran şair, işçiyi senelerin kış uykusundan uyanmasını istiyor. Sabir bu şiirinde: "Ey işçi, dünyayı yönetmek aslında senin elindedir; sen çalışmasan, zengin zengin olamaz, o senin alın terin sayesinde zenginleşmiştir. Bugün seni insan yerine koymuyorsa, uyan. Uyan ve hakkını iste, uyan ve mücadele yolunu bul.” diyor.

Bu çərxi-falak tərsina dövran edir indi,

Fəhla do özün daxili insan edir indi.

Olmaz bu ki, har amra dalalat eda fahla,

Dövlatli olan yerda casarat eda fahla,

Asuda nafas çakmaya halat eda fahla,

Yainki hüquq üstə adavat edə fəhlə. (s. 13)

Sadece bu birkaç mısra bile zannımızca, Sabir'in nasıl bir şair olduğunu ve şiirlerinin tüm zamanlara seslendiğini görmek açısından yeterli sayılabilir. Parçanın günümüz için de ne kadar güncel olduğu göz önündedir ve yoruma da ihtiyaç yoktur.

Sabir'in yaratıcılığı, onun yergi aynasında toplumun bütün köşelerine 1şık tutarak olumsuzluklarını yansıtması açısından diğer şairlerden ayrılır. Milletinin kız ve kadınlarını yabancıların bir naz ve cilvesine değişmekle milletinin yok oluşunu dikkate almayanlar da Sabir'in bıçak gibi keskin yergi kalemi dışında kalmamıştır.

Ey gül, nə acəb silsileyi-müşki-tərin var,

Ahu nazarin var!

Vey sarv, na xoş can alıcl qamzalarin var,

Ham işvalarin var!

Aldatdı cavanlarımızı nazü kirişmən,

Füruzeyi çeşmin! (s. 28) vs.

Çağdaş dönemde bütün insanlığın en sancılı yeri olan gençlerin eğitimi meselesine de şairin özgün bir bakışı vardır. Şair "Uşaqlara" ("Çocuklara") şiirinde kinayeli şekilde bu konuya değınmiştir:

Ey millatin ümmidi, dilü canı uşaqlar,

Olduz hərəniz bir evin oğlanı, uşaqlar,

Asuda gazin indi bu dünyanı, uşaqlar.

Indi buraxın balışı, yorğanı, uşaqlar,

Hom tork eliyin xaneyi-viranı, uşaqlar.

Gündo atınız bir neça patronu, uşaqlar,

Ta öyranosiz şiveyi-davanı, uşaqlar.

Adat qılasız harzavü-hadyani, uşaqlar,

Siz neyliyasiz madrasa, maktabi, uşaqlar. (s. 36-7)

Sabir'in yaratıcılığı bir deniz gibidir. Bugün Sabir'in halk arasında bir atasözüne dönüşmüş olan:

Dindirir asr bizi - dinmayiriz,

Atılan toplara diksinmayiriz,

Ocnabi seyra balonlarla çıxır,

Biz hala avtomobil minməyiriz. (s. 261) 
gibi mısraları geri kalmışlığımızın en güzel şekilde yergi diliyle ifadesidir.

Eğer günümüzle geçmişimizi kıyaslarsak, yerginin belirli dönemlerde, belirli zaman kesitlerinde şimşek gibi bir anlık çakıp yine yok olduğu kanaatine varırız. Şöyle ki, çağdaş dönemde yalnız Azerbaycan edebiyatında değil, dünya edebiyatında da yerginin aktüelliğini kaybettiği görülüyor. İlginç olan, dünyada meydana gelen bu kadar haksızlıkların, savaşların, adaletsizliklerin, vahşiliklerin merkezinde olduğumuz hâlde, bütün bunlara "dur!" diyecek keskin yergi eserlerinin yazılmasına tesadüf etmemektir. Eğer varsa da, yaygın olmadığından toplumun onlardan habersiz kalmasıdır. Yalnız sosyal ortamda bireylerin o ortamda bile kaybolup giden seslerini duyuyoruz. Fakat onları da destekleyip seslerini dünyaya duyurmalarını sağlayan kimse yok. Anlaşılan gelişme ve ilerleme olmamasına rağmen Sabir'in ve onun gibilerin cesareti daha çoktur. İlginç olan bir de Sabir'in bugün duracağı zirveyi görmesidir.

Seyli-ta'n oyla təməvvücla alıb dövrü-bərim-

Bənzərəm bir qocaman dağa ki, dəryadə durar!

Na qəm uğratsa da bir gün məni ifnayə zaman,

Man gedarsamsa, maramım yena dünyadə durar! (s. 87)

diyen şair kendi döneminde değer görmese de, birgün zirvede olacağını biliyordu.

Günümüzde yergi türüne ilginin olmamasını tabii ki, belirli seberlere bağlamak mümkündür. Fakat bunu toplumun tüm problemlerinin çözümü veya toplumun sadece olumlu yönde gelişimini sürdürmesiyle ilgilendirmek çocukça bir düşüncedir. Zannımızca, tersine, bugün insanlık uçuruma doğru gidiyor ve bütün dünya da bunun farkındadır. Başka bir deyişle, bugün yergiye evvekli dönemlerdekinden daha çok yer verilmeli ve daha sert biçimi olan istihzayı kullanmakla toplumun belalarını keskin şekilde eleştirmek gerekir.

Yergi ve eleştiri ateşine yalnız görevini kötüye kullanan memurlar değil, aynı zamanda o memurlar tarafından hukukları çiğnenen insanların durumuna seyirci kalan, hakkı yenen, fakat durumuna boyun eğenlerin de tutulması gerektir, çünkü toplumun her bir ferdinin vatandaş olarak olup bitenlere karşı mevkii, düşüncesi olmalıdır.

Yergi, onu yapanların manevi dünyasının şiirde yansımasıdır. Bir milletin saygıyla yaşaması için hayattan aldığı ders ve ruhuna işlemiş hastalıklar için ilaçtır. Yerginin esas gayesi halkın kültür geriliğini ortadan kaldırmak olduğundan bu sorumluluğu taşımada eleştiri onun için amaç değil, sadece bir araçtır. ${ }^{5}$

\section{Sonuç}

Azerbaycan edebiyatının en önemli şairlerinden olan Sabir, özellikle yergi şiirleri ile ön plana çıkmıştır. Yaşadığı dönemdeki toplumsal konulara eğilen şair ezilen halkın sesi olmaya, toplumdaki çeşitli sorunları yine topluma bir ayna gibi göstermeye ve bu sorunların çözümüne vesile olmaya çalışmıştır. Şairin dikkat çekici bir özelliği olarak karşımıza çıkan, sadece toplumsal konulara eğilmesi değil bunun ötesinde mizahi ve alaycı şiirlerindeki yaratıcılık ve yapmacıksız, sade üslubudur. Bu nedenle yazdığı şiirlerin birçoğu atasözü haline gelerek halkın belleğinde yer etmiştir ve dilden dile tekrar edilmektedir. Sabir'in bir özelliği de dönemindeki sorunlara karşı gösterdiği dirençteki cesaretidir. Bugün de geçmişte olduğu gibi Sabir'in dile getirdiği pek çok olumsuzluk aynen yaşandığı halde bu cesareti gösteren pek az kişi olması gerçekten şaşılacak bir durumdur. Sabir'in şiirleri genel olarak yergi edebiyatı, özel olarak da Azerbaycan edebiyatı sahası açısından hem edebî hem de toplumsal açılardan değerlendirilmesi ve ders alınması gereken birçok özelliği barındırmasından ötürü incelemeye değerdir.

\footnotetext{
${ }^{5}$ Mirze Alekper Sabir - 150, Bakü 2012, s. 53.
} 


\section{Kaynakça}

Ağazade, Yadulla, Azerbaycan Edebiyatında Satirik Poeziyanın Teşekkülü ve İnkişafi, Bakü 2013.

Bayramoğlu, Alhan, "Mirze Alekper Sabir”, Azerbaycan Jurnalı, Nu. 1, Bakü 2008.

Belinski, Vissarion Grigoryeviç, Sobrannıye Soçineniye v Tryox Tomax, C. II, OGIZ, GIXX, Moskova 1948.

Qocayeva, Adile, "Büyük Satirik Kasım Bey Zakir ve Onun Maarifçilik Faaliyeti”, Azerbaycan Jurnal, 4 Ağustos 2009, Bakü.

Mirze Alekper Sabir - 150, Bakü 2012.

Mirze Alekper Sabir, Hophopname, Bakü 1960.

Nabiyeva, İrade, “Sabir Hakkında Düşüncelerim”, Tehsil Problemleri, 1 Eylül 2016, Bakü. 